\title{
Association of Diabetic Retinopathy and Lipid Profile in Diabetic Patients in Mathura District
}

\author{
Nitin Singh Salaria', Malhar Vyas² \\ ${ }^{1}$ Associate Professor, Department of Ophthalmology, KD med college, Mathura, ${ }^{2}$ Senior Resident, Department of Ophthalmology, KD Medical College, Mathura.
}

\section{Abstract}

Background: It is estimated that diabetes mellitus affects 4 percent of the world's population, almost half of whom have some degree of diabetic retinopathy at any given time. Elevated serum lipid levels are associated with an increased risk of retinal hard exudate in persons with diabetic retinopathy. Therefore the current study was undertaken to determine the association of serum lipid profile with diabetic retinopathy and its severity. Subjects and Methods: One hundred fifty diabetic patients, out of these, 75 diabetic patients with retinopathy served as the study group I and 75 diabetic patients with no retinopathy formed group II (control group). Simultaneously, 75 age and sex matched healthy subjects were also studied as controls (group III). Serum total cholesterol, serum triglyceride, serum low density lipoprotein and serum high density lipoprotein were measured by using enzymatic method and autoanylyser. Fasting blood sugar and post prandial blood sugar were estimated by using GOD POD method. Results: Most of the patients in Group I had some degree of visual impairment. However there was no statistical significance with $\mathrm{p}>0.05$. The mean value of total cholesterol was higher in both group I and group II with value being higher in group1 $(229.09 \mathrm{mg} / \mathrm{dl})$ as compared to group II $(215.32 \mathrm{mg} / \mathrm{dl})$. Triglyceride levels also followed the similar trend with group I having mean value of $238.95 \mathrm{mg} / \mathrm{dl}$ and group II having $179.93 \mathrm{mg} / \mathrm{dl}$. But only total cholesterol value had statistical significance $\mathrm{p}<0.05$. Conclusion: The present study demonstrated statistically significant correlation between diabetic retinopathy and hypercholesterolemia. Increased cholesterol level was significantly associated with the occurrence of all grades of retinopathy especially severe NPDR, very severe NPDR and PDR. No correlation was found between lipid profile and visual acuity. These data suggest that hyperlipidaemia should be promptly treated in diabetic patients.

Keywords: Diabetes mellitus, Diabetic retinopathy, Hyperlipidaemia.

Corresponding Author: Dr. Malhar Vyas, Senior Resident, Department of Ophthalmology, KD Medical College, Mathura.

Received: October 2018

Accepted: November 2018

\section{Introduction}

It is estimated that diabetes mellitus affects 4 percent of the world's population, almost half of whom have some degree of diabetic retinopathy at any given time. ${ }^{[1,2]}$ According to WHO, diabetic retinopathy is responsible for $3-7 \%$ of the total blindness in Asia. ${ }^{[3]}$ In India the prevalence of diabetic retinopathy in general population is $3.5 \%$. and the prevalence of diabetic retinopathy in the population with diabetes mellitus is $18.0 \% .{ }^{[4]}$ In a population-based study in South India, diabetic retinopathy was detected in $1.78 \%$ of the diabetic patients screened. ${ }^{[5,6]}$ According to the World Diabetes Atlas, India is projected to have around 51 million people with diabetes. 7 There is a growing concern for Asia being the region for diabetic epidemic. ${ }^{[7,8]}$

Diabetic retinopathy is a very common, potentially preventable, long-term, microvascular complication of diabetes mellitus and a leading cause of visual disability and blindness. 9 While there are multiple risk factors which have been associated with the development and progression of diabetic retinopathy. However, dyslipidemia, microalbuminuria, BMI and smoking are some of the factors whose role as predictors of diabetic retinopathy is not well established. ${ }^{[10-12]}$

Diabetic retinopathy is frequently accompanied by lipid exudation. ${ }^{[13]}$ Elevated serum lipid levels are associated with an increased risk of retinal hard exudate in persons with diabetic retinopathy. ${ }^{[14]}$ The elevated lipid levels are also associated with endothelial dysfunction, which appears to play an important role in the pathogenesis of diabetic retinopathy, particularly in relation to the breakdown of blood-retinal barrier.

The association between serum lipid levels and diabetic retinopathy has been investigated in few studies. Some studies show a positive relationship between serum cholesterol and low-density lipoprotein levels and retinal hard exudation. Other studies show serum triglyceride levels as being important in the progression of retinopathy. Certain other studies show no relationship between serum lipid levels and diabetic retinopathy. ${ }^{[15]}$

The conflicting reports in the literature regarding the association between serum lipid levels and diabetic retinopathy and the paucity of studies relative to the existing case load warrants this study. Therefore the current study 
was undertaken to determine the association of serum lipid profile with diabetic retinopathy and its severity.

\section{Subjects and Methods}

This study was carried out in the department of Ophthalmology, department of Ophthalmology at KD Medical College, Mathura, from March 2018 to August 2018.

One hundred fifty (150) diabetic patients, out of these, 75 diabetic patients with retinopathy served as the study group I and 75 diabetic patients with no retinopathy formed group II (control group). Simultaneously, 75 age and sex matched healthy subjects were also studied as controls (group III).

Patients with age of more than 40 years with duration of diabetes more than 5 years were included in the study. Patients with significant hazy media which impairs visualization of the fundus and patients with pupillary abnormalities which prevent adequate dilatation for fundus visualisation or patients on hypolipidemic drugs were excluded from the study.

Data was collected using a piloted performa meeting the objectives of the study after an informed consent. A detailed history of each patient was obtained regarding the age, duration of diabetes, the anti-diabetic treatment they were on and any associated illness. The duration of diabetes was reckoned from the time of diagnosis.

\section{Ophthalmic evaluation}

All the study subjects had a thorough ophthalmic evaluation which included slit-lamp biomicroscopic examination of anterior segment, best corrected visual acuity (BCVA) of each eye recorded using Snellen chart, detailed fundus examination after mydriasis with $1 \%$ tropicamide and $5 \%$ phenylephrine eye drops using direct ophthalmoscopy, indirect ophthalmoscopy with $+20 \mathrm{D}$ lens and stereoscopic slit lamp biomicroscopy of the disc and macula using $+78 \mathrm{D}$ Volk lens. All cases were examined for the presence or absence of diabetic retinopathy. Those cases with fundus showing features of diabetic retinopathy were graded into five classes on the basis of ETDRS classification. ${ }^{[16]}$

\section{Biochemical Parameters}

$5 \mathrm{ml}$ of fasting blood sample was collected under asepsis from the anterior cubital vein using disposable syringe to assess lipid profile and blood sugar level. Postprandial blood sugar level estimation was also done. The following tests were carried out by enzymatic method using autoanylyser in the Central Laboratory with the help of the department of Biochemistry

Serum total cholesterol, serum triglyceride, serum low density lipoprotein and serum high density lipoprotein were measured by using enzymatic method 17 and autoanylyser. Fasting blood sugar and post prandial blood sugar were estimated by using GOD POD method. ${ }^{[17]}$

\section{Statistical analysis}

All group data were presented as frequency distribution (proportion) and the average value was presented as means $\pm \mathrm{SD}$ for the normal distribution data. ANOVA and Chisquare were used to interpret the results of the study. The $p$ value 0.05 was considered as significant. Data was analysed by using SPSS for windows software (version 16.0).

\section{Results}

Most of the patients had cataract of different grades and types. The percentage of subjects with normal anterior segment in group I, II and III were $20.0 \%, 28.0 \%$ and $22.66 \%$. There was no significant difference in anterior segment features in different groups. [Table 1]

Table 1: Anterior segment features in different groups

\begin{tabular}{|l|l|l|l|l|}
\hline $\begin{array}{l}\text { Anterior } \\
\text { segment }\end{array}$ & Group I & $\begin{array}{l}\text { Group } \\
\text { II }\end{array}$ & $\begin{array}{l}\text { Group } \\
\text { III }\end{array}$ & Total \\
\hline Normal & $15(20 \%)$ & $21(28 \%)$ & $\begin{array}{l}17 \\
(22.66 \%)\end{array}$ & $\begin{array}{l}53 \\
(23.55 \%)\end{array}$ \\
\hline Cataract & $40(53.33$ & 44 & 44 & 128 \\
& $\%)$ & $(58.66 \%)$ & $(58.66 \% 0$ & $(56.88 \%)$ \\
\hline $\begin{array}{l}\text { Pseudophaki } \\
\text { a }\end{array}$ & $\begin{array}{l}10 \\
(26.66 \%)\end{array}$ & $\begin{array}{l}10 \\
(13.33 \%)\end{array}$ & $\begin{array}{l}14.66 \%) \\
(18.55 \%)\end{array}$ \\
\hline
\end{tabular}

Most of the patients in Group I had some degree of visual impairment. However there was no statistical significance with $\mathrm{p}>0.05$. [Table 2]

\begin{tabular}{l}
\hline Table 2: Visual acuity distribution in each group. \\
\begin{tabular}{|l|l|l|l|l|}
\hline $\begin{array}{l}\text { Visual } \\
\text { Acuity }\end{array}$ & Group I & Group II & Group III & Total \\
\hline $6 / 6$ & $10(13 \%)$ & $49(65 \%)$ & $52(69.33 \%)$ & $\begin{array}{l}111 \\
(49.33 \%)\end{array}$ \\
\hline $6 / 9-6 / 12$ & $29(38 \%)$ & $11(14 \%)$ & $7(9.33 \%)$ & $47(20.88 \%)$ \\
\hline $6 / 18-6 / 36$ & $33(44 \%)$ & $13(17 \%)$ & $14(18.67)$ & $60(26.66 \%)$ \\
\hline$\leq 6 / 60$ & $3(4 \%)$ & $1(1.3 \%)$ & $2(2.6 \%)$ & $6(2.6 \%)$ \\
\hline
\end{tabular}
\end{tabular}

In the group I, Mild NPDR retinopathy was present in $44 \%$ of patients, moderate NPDR in $29 \%$ of patients, severe NPDR retinopathy in $10 \%$ of patients, very severe NPDR in $5 \%$ and proliferative retinopathy in $7 \%$ of patients. Among these 22 patients $(29.33 \%)$ had CSME. [Table 3]

Table 3: Distribution of severity of diabetic retinopathy and presence of CSME

\begin{tabular}{|l|l|l|}
\hline $\begin{array}{l}\text { Diabetic retinopathy } \\
\text { grade }\end{array}$ & Frequency & CSME \\
\hline Mild NPDR & $33(44 \%)$ & $11(50 \%)$ \\
\hline Moderate NPDR & $22(29 \%)$ & $7(31.81 \%)$ \\
\hline Severe NPDR & $8(10 \%)$ & $2(11 \%)$ \\
\hline Very Severe NPDR & $5(6.66 \%)$ & $1(5.5 \%)$ \\
\hline PDR & $7(9.33 \%)$ & $1(5.5 \%)$ \\
\hline Total & $75(100 \%)$ & $22(100 \%)$ \\
\hline
\end{tabular}

It is evident from fig 1 that the mean value of total cholesterol was higher in both group I and group II with value being higher in group $1(229.09 \mathrm{mg} / \mathrm{dl})$ as compared to group II $(215.32 \mathrm{mg} / \mathrm{dl})$. Triglyceride levels also followed the similar trend with group I having mean value of $238.95 \mathrm{mg} / \mathrm{dl}$ and group II having $179.93 \mathrm{mg} / \mathrm{dl}$. But only total cholesterol value had statistical significance $\mathrm{p}<0.05$. 


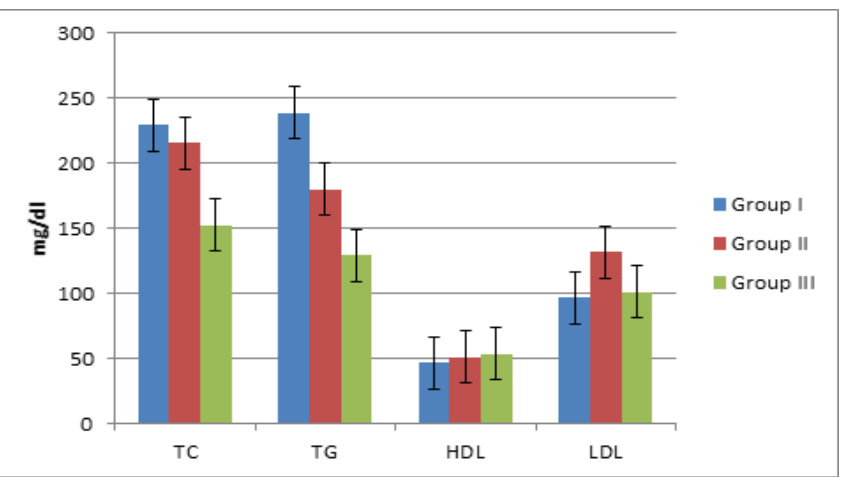

Figure 1: Mean values of lipid subfraction in each group.

[Figure 2] shows that FBS was significantly high in group I compare to group II and III. Similarly, PPBS level was significantly high in group II and III compare to diabetic retinopathy group I.

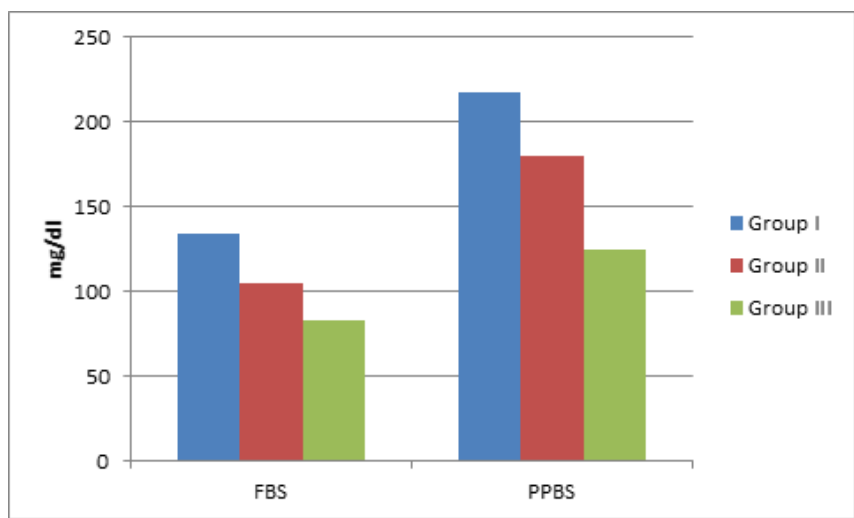

Figure 2: Mean values of blood sugar level in each group.

In group I, most of the patients, in all severity groups had raised total cholesterol $(72 \%)$ and raised triglyceride levels (92\%). However, only the rise in total cholesterol was statistically significant $(\mathrm{p}<0.05)$. [Table 4]

\begin{tabular}{|c|c|c|c|c|c|c|c|c|}
\hline \multirow{2}{*}{$\begin{array}{l}\text { Lipid } \\
\text { profile }\end{array}$} & \multirow[t]{2}{*}{ Category } & \multicolumn{5}{|c|}{ Diabetic Retinopathy } & \multirow[t]{2}{*}{ Total } & \multirow[t]{2}{*}{ P value } \\
\hline & & Mild NPDR & $\begin{array}{l}\text { Moderate } \\
\text { NPDR }\end{array}$ & $\begin{array}{l}\text { Severe } \\
\text { NPDR }\end{array}$ & $\begin{array}{l}\text { Very severe } \\
\text { NPDR }\end{array}$ & PDR & & \\
\hline \multirow[t]{2}{*}{$\mathrm{TC}$} & High & $25(75.75 \%)$ & $12(54.54 \%)$ & $7(87.5 \%)$ & $4(80 \%)$ & $6(88.9 \%)$ & 54 & \multirow[t]{2}{*}{$<0.05$} \\
\hline & Normal & $8(24.24 \%)$ & $10(45.45 \%)$ & $1(12.5 \%)$ & $1(20 \%)$ & $1(14.2 \%)$ & 21 & \\
\hline \multirow[t]{2}{*}{ TG } & High & $30(90 \%)$ & $20(90.9 \%)$ & $7(87.5 \%)$ & $5(100 \%)$ & $7(100 \%)$ & 69 & \multirow[t]{2}{*}{$>0.05$} \\
\hline & Normal & $3(10 \%)$ & $2(9.09 \%)$ & $1(12.5 \%)$ & $0(0 \%)$ & $0(0 \%)$ & 6 & \\
\hline \multirow[t]{2}{*}{ HDL } & Low & $3(10 \%)$ & $2(9.09 \%)$ & $2(25 \%)$ & $2(40 \%)$ & $3(42.5 \%)$ & 12 & \multirow[t]{2}{*}{$>0.05$} \\
\hline & Normal & $30(90 \%)$ & $20(90.9 \%)$ & $6(75 \%)$ & $3(60 \%)$ & $4(47.5 \%)$ & 63 & \\
\hline \multirow[t]{2}{*}{ LDL } & High & $1(3.03 \%)$ & $3(12.1 \%)$ & $1(12.5 \%)$ & $1(20 \%)$ & $0(0 \%)$ & 6 & \multirow[t]{2}{*}{$>0.05$} \\
\hline & Normal & $32(96.9 \%)$ & $19(86.36 \%)$ & $7(87.5 \%)$ & $4(80 \%)$ & $7(100 \%)$ & 69 & \\
\hline
\end{tabular}

Table 5: Mean values of the lipid subfractions in subjects categorized according to severity of diabetic retinopathy

\begin{tabular}{|l|l|l|l|l|l|l|}
\hline $\begin{array}{l}\text { Lipi } \\
\text { d } \\
\text { prof } \\
\text { ile }\end{array}$ & MPDR & $\begin{array}{l}\text { ate } \\
\text { NPDR }\end{array}$ & $\begin{array}{l}\text { NPDere } \\
\text { NPD }\end{array}$ & $\begin{array}{l}\text { Very } \\
\text { severe } \\
\text { NPDR }\end{array}$ & PDR & Group \\
& & & & & \\
TC & $215.6 \pm$ & $221.3 \pm$ & $235.0 \pm$ & $234.4 \pm$ & $254.67 \pm$ & $229.0 \pm$ \\
& 30.6 & 49.4 & 39.7 & 44.7 & 35.6 & 30.0 \\
\hline TG & $241.1 \pm$ & $232.4 \pm$ & $245.7 \pm$ & $231.0 \pm$ & $243.0 \pm 1$ & $179.9 \pm$ \\
& 16.9 & 18.8 & 22.2 & 26.7 & 3.6 & 20.4 \\
\hline HD & $48.7 \pm 9$. & $47.5 \pm 4$. & $45.72 \pm$ & $40.4 \pm 7$. & $42.56 \pm 1$ & $51.3 \pm 1$ \\
L & 1 & 9 & 10.8 & 8 & 0.8 & 3.7 \\
\hline LD & $92.1 \pm 1$ & 106.03 & $80.45 \pm$ & $97.8 \pm 1$ & $166.22 \pm$ & $131.9 \pm$ \\
L & 8.9 & \pm 20 & 22.3 & 3.7 & 27.0 & 16.3 \\
\hline
\end{tabular}

[Table 5] shows serum total cholesterol concentrations were higher in subjects with severe NPDR, very severe NPDR and PDR compared with subjects without DR ( $p<0.05)$.

\section{Discussion}

Hyperglycemia and dyslipidemia are two major metabolic disorders seen in patients with diabetes mellitus. Despite considerable progress in understanding of hyperglycemiainduced disease over the past decade, the link between diabetic metabolic disorders and retinopathy still eludes us.
18 This study aimed to determine the relationship between serum lipid profile and the severity of diabetic retinopathy in type 2 diabetes patients.

The present study showed statistically significant correlation between diabetic retinopathy and raised total cholesterol level ( $p<0.05)$. Increased cholesterol level was significantly associated with the occurrence of all grades of retinopathy. The mean value of total cholesterol in group I was higher comparing to group II and group III. The mean triglyceride level was also higher in group I as compared to group II and group III. However, this correlation was not statistically significant $(\mathrm{p}>0.05)$. These findings are very similar to the previous study of Al-Bdour et al. ${ }^{[1]}$ as they observed positive relation between diabetic retinopathy and hypercholesterolemia $(\mathrm{p}<0.05)$. Similarly, Larsson et al, ${ }^{[19]}$ also found significant correlation between higher levels of serum total cholesterol and retinopathy. Alike, Rema et al, ${ }^{[20]}$ recorded the association of serum lipids with diabetic retinopathy in urban South Indians. The serum triglyceride $(\mathrm{p}=0.001)$ levels and total cholesterol $(\mathrm{P}=0.014)$ were higher in patients with diabetic retinopathy as compared to those without diabetic retinopathy. This association was maintained even after adjusting for age, as age by itself is a significant risk factor for hyperlipidemia. Similar results were obtained by Haddad et al. ${ }^{[1]}$ In the present study although both total cholesterol and triglyceride levels were 
elevated in group I as compared to group II and group III, only hypercholesterolemia was statistically significant.

The Hoorn Study, a large population based study to determine the potential risk factors for retinopathy in diabetic and nondiabetic individuals showed that retinopathy, and hard exudates in retinopathy in particular, are related to elevated serum total and LDL cholesterol levels. ${ }^{[22]}$ Agarwal et al, ${ }^{[23]}$ and Sachdev et al, ${ }^{[24]}$ also observed raised level of total and LDL cholesterol and reduced level of HDL/LDL cholesterol ratio in patients with diabetic retinopathy. These results are partly in concordance with the present study as hypercholesterolemia but not hypertriglyceridemia was found to be a risk factor for retinopathy in the current study.

In the present study serum total cholesterol concentrations were higher in subjects with severe NPDR, very severe NPDR and PDR compared with subjects without DR ( $\mathrm{p}<$ 0.05 ). Except for this parameter, there were no significant differences in the lipid concentrations with the severity of DR. Elevated triglyceride were found to be a significant risk factor for moderate and severe non-proliferative retinopathy and proliferative retinopathy even after adjustment for age, duration of diabetes, $\mathrm{HbAlc}$, and albumin excretion rate in EURODIAB study. ${ }^{[25]}$ In CURES eye study serum cholesterol concentrations were higher in subjects with moderate NPDR compared with subjects without DR (p $<0.05)$. Triglyceride concentrations were higher in those with mild NPDR compared with those without DR (p $<0.05)$. ${ }^{[26]}$

The present study found a significant association between hypercholesteremia and CSME ( $\mathrm{p}<0.05)$. This was in accordance with the study by Al-Bdour et $\mathrm{al},{ }^{[1]]}$ who found significant association between the development of diabetic maculopathy and hypercholesteremia. Similarly, higher total cholesterol level was positively associated with presence of CSME, in a cross-sectional analysis of participants with diabetes in the Wisconsin Epidemiological Study of Diabetic Retinopathy (WESDR). ${ }^{[26]}$ Alike, CURES eye study also showed an association of Diabetic macular edema in type 2 diabetic subjects with increased cholesterol level. ${ }^{[20]}$ In a prospective analysis of ETDRS data, the development of CSME was 50\% faster among subjects with elevated baseline levels of total cholesterol and triglycerides. ${ }^{[27]}$ Ucgun et al also showed a positive relationship between CSME and hypercholesteremia. ${ }^{[28]}$

The present study did not show any trend of increase in the severity of diabetic retinopathy with the increasing levels of different serum lipid subfractions. Larsson et al, ${ }^{[19]}$ showed a linear relationship of serum cholesterol levels with severity of diabetic retinopathy. WESDR study also found that there was a significant trend for increasing severity of diabetic retinopathy with increasing cholesterol. ${ }^{[20]}$

Most of the diabetics in the present study had poor glycemic control. Hyperglycemia is also associated with dyslipidemia, specifically increased levels of total cholesterol and triglycerides, a slight elevation of LDL, but generally little if any change in HDL. Consequently hyperglycemia may be an important confounding factor in the study with respect to both diabetic retinopathy and hypercholesterolemia. ${ }^{[16,19,22]}$

\section{Conclusion}

The present study demonstrated statistically significant correlation between diabetic retinopathy and hypercholesterolemia. Increased cholesterol level was significantly associated with the occurrence of all grades of retinopathy especially severe NPDR, very severe NPDR and PDR. It also showed that hypercholesterolemia is significantly associated with CSME. No correlation was found between lipid profile and visual acuity. These data suggest that hyperlipidaemia should be promptly treated in diabetic patients. However, further studies are required to establish the causal relationship between dyslipidemia and diabetic retinopathy.

\section{References}

1. Aiello LP, Gardner TW, King GL, Blankenship G, Cavallerano JD, Ferris FL 3rd, et al. Diabetic retinopathy. Diabetes Care 1998; 21: 143 56 .

2. Wild S, Roglic G, Green A, Sicree R, King H. Global prevelance of Diabetes. Estimates for the year 2000 and projections for 2030. Diabetes Care 2000; 27: 1047-1053.

3. Meyer JJ, Wang C, Shukla D, Rajendran A, Liang X, Tang S et al. Diabetic Retinopathy in Asia. Catarct and refractive surgery today. 2005 Oct: 64-68.

4. Raman R, Rani PK, Rachepalle SR, Gnaanamurthy P, Uthra S, GovindasamyK, Sharma T. Prevalence of Diabetic Retinopathy inIndia: Sankara Nethralaya Diabetic Retinopathy Epidemiology and Molecular Genetics Study Report 2. Ophthalmology 2009; 116(2): 311-318.

5. Dandona R, Dandona L, Naduvilath TJ, McCarty A, Rao GN. Population based assessment of diabetic retinopathy in an urban population in southern India. Br. J. Ophthalmol. 1999; 83: 937- 940.

6. Sharma RA. Diabetic eye disease in southern India. J Comm Eye Health 1996; 09(20): 56-58

7. Anjana RM, Ali MK, Pradeepa R, Deepa M, Datta M, Unnikrishnan et al. The need for obtaining accurate nationwide estimates of diabetes prevalence in India - Rationale for a national study on diabetes. Indian J Med Res. 2011 April; 133(4): 369-380.

8. Subhan SS, Rahman, Sayeed A, Hasin F, Karim R, Alif L. The Role of Duration of Diabetes in the Development of Diabetic Retinopathy in Young Diabetic patients in Bangladesh. J Bangladesh Coll Phys Surg 2009; 27: 133-138.

9. Miljanovic B, Glynn RJ, David M, Nathan, Joann E, Manson, Debra A et al. Prospective Study of Serum Lipids and Risk of Diabetic Macular Edema in Type1 Diabetes. Diabetes 2003 Nov; 53: 2883 - 2902.

10. Stephen Ryan. RETINA. 4th ed. Vol. II. Chapter 66. In: Etiologic mechanisms in Diabetic retinopathy, Robert N. Frank, eds. Philadelphia PA: Elsevier; 2006: 1241 - 1265.

11. Muawyah D Al-Bdour, Maha I Al-Till, Khawla M Abu Samra. Risk factors for diabetic retinopathy among Jordanian diabetics. Middle East African Journal of Ophthalmology 2008; 15: 77-80.

12. Hamilton AMP, Ulbig MW, Polkinghorne P. Management of diabetic retinopathy. BMJ Publishing group, London,1996.

13. Chowdhury TA, Hopkins D, Dodson PM, Vafidis DF. The role of serum lipids in exudative diabetic maculopathy: is there a place for lipid lowering therapy? Eye 2002 (16): 689-693.

14. Reanita, Bardosono S, Victor AA. Relationship between plasma lipid profile and the severity of diabetic retinopathy in type 2 diabetes patients. Med J Indones 2008; 17: 221-225.

15. D H W Su, K T Yeo. Diabetic Retinopathy and Serum Lipids. Singapore Med J 2000; 41(6): 295-297.

16. R Joseph Olk and Carol M. Lee. Diabetic retinopathy: Practical management. Chapter 2. In: Classification of Diabetic Retinopathy. 
Philadelphia PA: Lippincott; 1993: 5-18.

17. Klein R, Klein BEK, Moss SE, Davis MD, Demets DL. The Wisconsin epidemiologic study of diabetic retinopathy III. Prevalence and risk of diabetic retinopathy when age at diagnosis is 30 or more years. Arch Ophthalmol 1984; 102: 527-32.

18. Weiqin Chen, Donald B. Jump, Maria B. Grant, Walter J. Esselman, and Julia V. Busik. Dyslipidemia, but Not Hyperglycemia, Induces Inflammatory Adhesion Molecules in Human Retinal Vascular Endothelial Cells. IOVS, 2003 Nov; 44(11): 5016-5022.

19. Lill-Inger Larsson, Albert Alm, Folke Lithner, Gosta Dahlen, Reinhold Bergstrom The association of hyperlipidemia with retinopathy in diabetic patients aged 15-50 years in the county of Umea. Acta Ophthalmol. Scand. 1999; 77: 585-591.

20. Rema M, Srivastava BK, Anitha B, Deepa R, Mohan V. Association of serum lipids with diabetic retinopathy in urban South Indians-the Chennai Urban Rural Epidemiology Study (CURES) Eye Study-2. Diabetic Medicine 2006; 23: 1029-1036.

21. Haddad E, Ossama A W, Mohammed Kamal Saad. Prevalence and risk factors for diabetic retinopathy among Omani diabetics. $\mathrm{Br} \mathrm{J}$ Ophthalmol 1998; 82: 901-90.

22. VanLeiden AH, Dekker JM, Moll AC, Giel Nijpels, Heine RJ, Bouter LM et al. Blood Pressure, Lipids, and Obesity Are Associated With Retinopathy: The Hoorn Study.Diabetes Care 2002; 25: 1320-132.

23. Agarwal RP, Meeta Singla, Vyas SP, Sabir Hussain, Jain GC, Kochar
DR. Prevalence of retinopathy and its relation with various risk factors in type 1 diabetes mellitus-hospital based study India. International Journal of Diabetes in Developing Countries 2001; 21: 184-190.

24. Sachdev N, Sahni A. Association of systemic risk factors with the severity of retinal hard exudates in a north Indian population with type 2 diabetes. J Postgrad Med 2010 Sep; 56: 3-6.

25. Sjolie AK, Stephenson J, Aldington S, et al. Retinopathy and vision loss in insulin-dependent diabetes in Europe. The EURODIAB IDDM Complications Study. Ophthalmology 1997 Feb; 104(2): 252-60.

26. Klein BEK, Moss SE, Klein R, Surawicz TS. The Wisconsin Epidemiologic Study of Diabetic Retinopathy(WESDR), XIII: relationship between serum cholesterol to retinopathy and hard exudate. Ophthalmology 1991; 98: 1261-5.

27. Chew EY, Klein ML, Ferris FL 3rd, Remaley NA, Murphy RP, Chantry $\mathrm{K}$ et al. Association of elevated serum lipid levels with retinal hard exudate in diabetic retinopathy. Early Treatment Diabetic Retinopathy Study (ETDRS) Report 22. Arch Ophthalmol. 1996 Sep;114:1079-84.

28. Uçgun NI, Yildirim Z, Kiliç N, Gürsel E. The importance of serum lipids in exudative diabetic macular edema in type 2 diabetic patients. Annals of the New York Academy of Sciences 2007 Apr.; 1100: 213 217.

Copyright: (C) the author(s), 2019. It is an open-access article distributed under the terms of the Creative Commons Attribution License (CC BY 4.0), which permits authors to retain ownership of the copyright for their content, and allow anyone to download, reuse, reprint, modify, distribute and/or copy the content as long as the original authors and source are cited.

How to cite this article: Salaria NS, Vyas M. Association of Diabetic Retinopathy and Lipid Profile in Diabetic Patients in Mathura District. Asian J. Med. Res. 2019;8(1):OT01-OT05.

DOI: dx.doi.org/10.21276/ajmr.2019.8.1.OT1

Source of Support: Nil, Conflict of Interest: None declared.

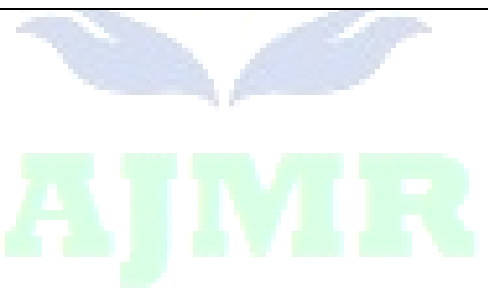

